of oppression will grow? Feminist Social Psychology answers that question with a resounding 'yes'. Psychoanalytically inclined feminism, such as is represented in Sexual Contradictions, is much more equivocal. We cannot ignore our experience but neither can we view it as unambiguously transparent to reflection. The concept of the unconscious precludes such a notion of transparency. We need theoretical concepts as much as critical and shared self-reflection. However inadequate, psychoanalysis provides the base for such concepts. The authors of Feminist Social Psycho$\log y$ will not agree.
Clearly, there are many points on which these two books are opposed, where different ideas are singled out as central or the same ideas are dealt with in conflicting ways. Psychology and psychoanalysis still find it hard to communicate, even in their feminist guises. On the other hand, the books share in common a commitment to understanding the subjective elements of oppression in ways that do not reduce our mental and emotional lives totally to social determinants. I find this an exciting development and hope that the intervention of feminism in psychology will grow.

Diana Adlam

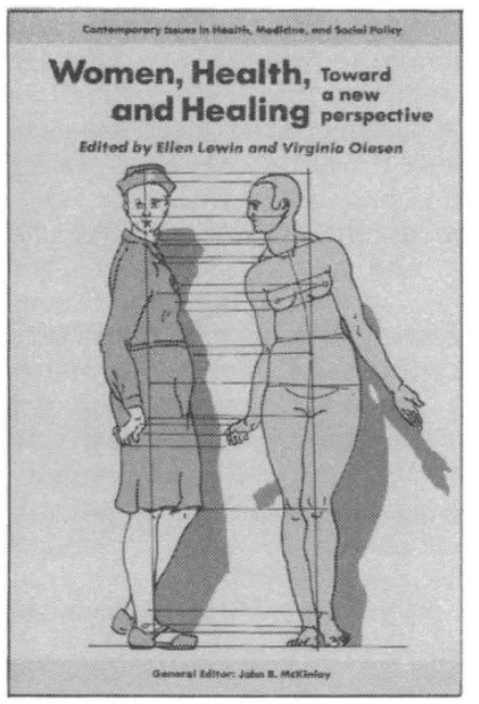

\section{Women, Health and Healing: Towards a New Perspective}

Ellen Lewin and Virginia

Olesen (Eds)

Tavistock London, 1985

ISBN $0422780200 £ 15.95 \mathrm{Hbk}$

ISBN $0422780308 £ 9.95 \mathrm{Pbk}$

This book is a valuable collection of original articles that brings together some contemporary de- velopments in feminist scholarship in the field of women's health on both sides of the Atlantic. Doing so has brought with it some difficulties, but much that also moves both our analyses and political struggle forward.

In their introduction, Ellen Lewin and Virginia Olesen outline what they see as traditional orientations to women's health issues which they hope their volume moves away from; these include the almost exclusive focus on aspects of women's reproductive life, and the operation of sexist stereotyping and its consequences in diagnoses, treatment and care. In this I think they have been successful. Thus, while it is important not to regard such issues as now obsolete they are moved into areas of more contemporary relevance; for example, in Patricia Kaufert and Sonia McKinlay's article on the development and use of estrogen replacement therapy; in Shelley Romalis's analysis of the struggle over the provision of alternative birthing practices in Canada; and in Rosalind Petschesky's timely contribution which discusses both state and medical control factors in the US that determine the access to abortion in the $1980 \mathrm{~s}$, 
and its construction as an issue of morality not health. Furthermore, as these articles themselves demonstrate, it is essential to move the ground from an understanding of women's experiences of health care to one which puts these experiences in the broader socio-political context.

In addition the volume presents us with new topics in the field which have been either absent or poorly developed in the past. Lewin and Olesen themselves have contributed to this with their work on the occupational health of clerical workers. An examination of the health consequences of paid (and indeed unpaid) work has been relatively neglected as a focus for analysis and struggle, and within the women's occupational health movement itself clerical workers have only recently been subject to the same kind of scrutiny as those women who work in more 'hazardous' areas. Many feminists in Britain and America now believe that work (along with factors such as poverty, housing and unemployment) is a necessary focus if we are to understand the social and political forces that produce ill-health or indeed health. Both Lesley Doyal, in her contribution on women as patients and providers in the NHS which shows that a society also structured by inequalities of class and race has a major impact on patterns of ill-health and access to health care, and Mary Boutilier and Lucinda San Giovani's article on sport and physical fitness demonstrate shifts of analysis in these directions, although they differ in other respects.

Older women have also been neglected in our work and in policy development, not unrelated perhaps to previous preoccupations with the reproductive career. Helen Evers not only reminds us of that invisibility in both policies and institutional arrangements that are aimed at the 'care' of the predominantly female elderly population, but also demonstrates the disjuncture between such 'macro'-level social arrangements and individual subjective experience. The relation of community care policies to the reality of women's lives as carers and cared for is also relevant to Hilary Graham's analysis of the unpaid and also largely invisible health work of women. While for Evers it is principally care that is at issue, Graham extends our concepts of unpaid health work by women beyond care to encompass providing the material conditions which are the means by which health is achievable and maintained, as well as to a mediating role between the family and the state in the form of officially delivered services. As the editors point out, the concern with unpaid 'hidden' labour has been a mainly British concern. It seems essential that both feminist and traditional sociological analyses are challenged in the way Graham has done if they are adequately to develop accounts of the labour market and women's work that recognize the intersection of its sexual and spatial divisions. There is, however, also an inherent danger in stressing the importance of new forms of health work. As Helen Evers reminds us, women are not only carers but cared for, and have experiences and views of the relationships and social processes involved. They are not simply objects of work. Social policies too will need to take account of the people to whom those policies are directed.

There is, then, in a number of contributions a theoretical importance attached to understanding meanings and values as they relate to women's experiences in everyday life as well as the social context which shapes those experiences. Attention is drawn to the way in which political values and political institutions (in which I include medicine and law as well as the state) have determined the form and content of health-care delivery in both North America and Britain, and the responses and strategies 
women have developed in relation to it. But everyday experiences and political forces are also mediated by the inequalities of gender, race and class, which determine more particular patterns of health and illhealth, access to resources and care, and the opportunities and costs in the health-care division of labour.

The themes outlined above are those which the volume addresses through some of its contributions. However, it also seems to me that it does not achieve any theoretical consistency, and indeed its presumed commitment to feminism remains loosely defined and disparate. Thus it seems that the development of effective strategies for women's health in the future would be required to take a number of different forms. It is hard to support its claim to be a new perspective. This is probably inevitable, not only with a collection such as this one, but with the nature of the women's movement itself. Perhaps one of the strengths of this movement over time has been its amorphous character, allowing attacks on all fronts and consciousness to be developed from experience and from specific issue-based struggles, as well as from the general discriminatory and oppressive forces of a patriarchal social order.

The book points to the cultural and historical specificity that also needs to be accommodated. As Margaret Stacey shows, the US and Britain differ considerably in these respects, evolving different political/ judicial institutions and processes, and different systems of health-care delivery. The women's health movement in each country has therefore addressed different issues, addressed them in a different way, or found issues taking a different focus in relation to their own developmental histories (as is the case with abortion). For example, the collection includes an examination of women and sport. I admit I found this odd, a reflection of my ethnocentric notions of what a sociology of women's health includes. In Britain, where issues of women's participation in sport have remained in the arena of the sociology of leisure or sociology of sport, we might ask why not health and illness? However, because I share Margaret Stacey's sentiment that mutual understanding is a way of forwarding common struggle, the differences become as important as the similarities in developing our analysis and our movement.

This book does therefore have considerable value. It's given us something but not everything. It still leaves us with areas that are unexplored. It shifts us, but not far enough, from traditional conceptions of women as providers and recipients of health care. The focus of much of the analysis is still the interface between women and a male and medically dominated health-care system. While this will still be important in the day-to-day health experiences of most women and therefore needs exploring, there are other areas to be examined. In spite of its title, there is little that contributes toward a positive reevaluation of women's roles as healers (except in Hilary Graham's work) in both traditional and new forms of health-care delivery. Women's involvement in 'alternative' health care, and in the construction of new knowledge, now needs attention. Particular groups of women continue to be less visible than others, in particular Black women. The recognition in this volume of the importance of political forces in the oppression of women will need extending to encompass the experiences of particular women, not just all women here in the UK, the US and elsewhere.

\section{Barbara Harrison}

